\title{
Políticas de ampliação da jornada escolar para o Ensino Médio no Rio Grande do Sul: um estudo sobre o conhecimento escolar*
}

Roberto Rafael Dias da Silva a

\section{Resumo}

O presente artigo objetiva fazer um mapeamento das estratégias políticas de constituição do conhecimento escolar nas políticas de ampliação da jornada para o Ensino Médio no Estado do Rio Grande do Sul, considerando o cenário das políticas curriculares da última década (2002-2012). Com essa intenção, o estudo inscreve-se no campo dos Estudos Curriculares, sobretudo aqueles vinculados à tradição crítica, seja por meio dos estudos sociológicos do conhecimento escolar, seja pelos estudos políticos sobre a instituição escolar em sociedades neoliberais. Sob diferentes formatos, percebeu-se que a proteção social, o desenvolvimento econômico e a personalização dos percursos são algumas das racionalidades políticas orientadoras das referidas políticas. Em comum nas diferentes políticas, podemos indicar a ausência de uma concepção do conhecimento escolar dimensionada em sua objetividade e, ao mesmo tempo, justificada pelo seu caráter formativo. Os processos de seleção dos conhecimentos são regidos por sistemas de raciocínio pedagógico produzidos de forma exógena aos processos escolares, direcionando-os para o atendimento de demandas sociais e econômicas.

Palavras-chave: Políticas curriculares. Conhecimento escolar. Ensino Médio.

O que foi feito do ideal de transmitir a cultura e, mais especificamente, uma "cultura comum" a todos os cidadãos através da escola?

(DUSSEL, 2009, p. 352).

\footnotetext{
a Universidade de Caxias do Sul - UCS, Programa de Pós-Graduação em Educação, Doutor em Educação. Caxias do Sul, Rio Grande do Sul, Brasil.

* A pesquisa da qual este artigo deriva contou com financiamento do CNPq.
}

Recebido em: 30 mai. 2014

Aceito em: 21 mar. 2015 


\section{Introdução}

Nossa trajetória de pesquisa tem sido delineada a partir de uma intensa preocupação com a instrução juvenil, em suas diferentes nuances. O Ensino Médio, enquanto espaço formativo privilegiado para as juventudes, apresentou-se como um objeto privilegiado de nossos estudos, tanto no que se refere aos materiais midiáticos produzidos aos estudantes e professores, quanto às condições de trabalho docente e aspectos curriculares referentes a essa etapa da Educação Básica. Recentemente temos iniciado um movimento na direção de examinar criticamente as políticas de constituição do conhecimento escolar para o Ensino Médio, considerando as intensas reformas produzidas ao longo das últimas décadas, ao mesmo tempo em que situando essa etapa da Educação Básica como um espaço de significativas desigualdades educacionais (SILVA, 2014; SILVA; PEREIRA, 2013). Com o presente estudo, pretendemos levar adiante algumas de nossas preocupações investigativas acerca dos currículos escolares para o Ensino Médio no Brasil.

Atualmente, ao examinarmos as políticas contemporâneas de escolarização, nos contextos nacional e internacional, faz-se possível observar uma tendência na mobilização de práticas de ampliação da jornada escolar (CAVALIERE, 2007; COELHO, 2009). Em geral, tais políticas consideram a ampliação do tempo escolar em uma perspectiva de ressignificação das culturas escolares, tanto no que se refere a uma multiplicação de programas de proteção social, quanto no que se refere a deslocamentos nos sentidos da qualidade pedagógica dos processos formativos na Educação Básica. Do ponto de vista teórico, reitera-se que essa problemática tem perpassado tanto a produção analítica de diferentes perspectivas teóricas (SACRISTÁN, 2008), quanto contextos múltiplos e diferenciados (CATTABRINNI, 1997).

No contexto brasileiro, ainda que a emergência da temática seja decorrente dos movimentos de renovação pedagógica da primeira metade do século XX (TEIXEIRA, 1978;1994), nas últimas duas décadas notamos um movimento de consolidação da temática da ampliação do tempo escolar (CAVALIERE, 2007; MOLL, 2012), movimento visibilizado tanto na literatura contemporânea, quanto no ordenamento curricular das escolas brasileiras. Tal consolidação, de forma geral, é produzida sob as condições de atendimento aos delineamentos históricos da educação brasileira, sobretudo no que tange ao artigo 34 da Lei n ${ }^{\circ}$ 9.394/96, que versa sobre a possibilidade de ampliação dos tempos escolares na Educação Básica (BRASIL, 1996). Atualmente, com a multiplicação de novos programas governamentais, intensificaram-se iniciativas nessa direção sobretudo com ações multissetoriais como os programas Mais Educação, Segundo Tempo ou Ensino 
Médio Inovador, dentre outros ${ }^{1}$. De forma a reforçar esse cenário, ainda precisamos destacar que o novo Plano Nacional de Educação (PNE 2014-2024) encaminha, em sua meta 6 , a ampliação da jornada escolar em $50 \%$ das escolas brasileiras até o ano de 2024. Enfim, parece-nos que a ampliação da jornada escolar tem estado na ordem do dia das políticas de escolarização brasileiras.

Diferentes conjuntos argumentativos têm sido produzidos pela sociedade brasileira que visam justificar a implementação dessas novas políticas educacionais. Em geral, tais abordagens argumentam acerca de uma ressignificação das configurações culturais das famílias brasileiras, pelos novos condicionantes sociais derivados da ocupação do mercado de trabalho pelas mulheres e também pelas restrições normativas ao trabalho infantil, pelos controles políticos das novas demandas coletivas vinculadas ao risco ou à vulnerabilidade social, bem como pela melhoria das condições de qualidade das escolas públicas brasileiras e a consequente melhoria do desempenho dos estudantes nas avaliações de larga escala (CAVALIERE, 2009; BRANDÃO, 2009). Assim sendo, de diferentes modos a ampliação da jornada escolar no Brasil tem perpassado os diferentes programas políticos da última década, fabricando um conjunto de novos sistemas de raciocínio pedagógico que tendem a regular as práticas escolares de nosso País.

De forma específica, interrogaremos no presente artigo os modos pelos quais estamos tratando o conhecimento escolar nas políticas curriculares de ampliação da jornada escolar para o Ensino Médio no Brasil. Acerca do delineamento empírico para esse estudo, optamos pelo Estado do Rio Grande do Sul devido ao fato de que, neste contexto, observamos em funcionamento três políticas curriculares que, concomitantemente, recomendam a ampliação da jornada para esta etapa da Educação Básica, a saber: a) a implantação do Ensino Médio Politécnico, política a nível estadual que estabelece a ampliação da jornada semanal para 30 horas-aula; b) a vinculação da rede pública estadual ao Programa Ensino Médio Inovador (PROEMI) do Ministério da Educação, no qual as atividades pedagógicas das escolas de baixo IDEB são complementadas com oficinas e outras dinâmicas de diversificação curricular; c) escolas de tempo integral, ainda em um formato aproximado aos Centros Integrados de Educação Pública (CIEP), herdadas do início da década de 1990 da administração do Partido Democrático Trabalhista no referido contexto.

Articulados ao campo dos Estudos Curriculares, sobretudo em suas vertentes críticas, de um ponto de vista teórico, direcionaremos nossa argumentação para

\footnotetext{
1 No que tange ao Ensino Médio, as recentes Diretrizes Curriculares Nacionais para o Ensino Médio (BRASIL, 2012), em seu artigo 14, esboçam a possibilidade de regimes de tempo integral, de sete horas diárias, para a organização curricular dessa etapa da Educação Básica.
} 
a perspectiva de que, em nossa Contemporaneidade, o conhecimento escolar tem sido secundarizado nas políticas (e nas práticas) curriculares alternativas, o que pode estar encaminhando, consequentemente, a um cenário de ressignificação das funções sociais da instituição escolar. Para fins dessa proposta investigativa, contextualmente, consideramos como cenário a emergência de uma cultura do novo capitalismo, tal como sugere o sociólogo Richard Sennett (2006).

Com essa intenção exposta, argumentamos que não produziremos nenhuma análise pontual dos documentos curriculares brasileiros, nem mesmo trataremos de seus limites e possibilidades. Estabeleceremos uma abordagem transversal sobre diferentes aspectos que se inserem nessas pautas curriculares. Examinar as políticas curriculares em nosso País, na última década, tem se apresentado como um grande desafio, visto que se intensificaram novas políticas de ampliação do acesso e de democratização da permanência nos diferentes níveis de ensino. É inegável a intensidade política que experimentamos neste tempo, no qual os diferentes grupos sociais que historicamente foram segregados das políticas de escolarização têm seus direitos sociais e políticos em processo de consolidação. Face a essa consideração, nosso interesse estará em estabelecer um diagnóstico acerca do processo de implementação em curso, ao mesmo tempo em que produziremos uma crítica política de seu contexto de influência e de seus modos de operação.

\section{O conhecimento escolar em políticas curriculares alternativas: uma revisão}

Para iniciar essa seção, tomamos como ponto de partida um texto do professor José Carlos Libâneo, publicado recentemente, intitulado "O dualismo perverso da escola pública brasileira: escola do conhecimento para os ricos, escola do acolhimento social para os pobres". Segundo o pesquisador, as condições políticas e econômicas das últimas duas décadas, demarcadas a partir da Conferência Mundial de Educação para Todos realizada no ano de 1990, conduziram o Estado brasileiro a uma forte aproximação com as pautas políticas dos organismos internacionais (ROBERTSON, 2012; SHIROMA; GARCIA; CAMPOS, 2011). Concomitantemente, pulverizaram-se os discursos críticos sobre os modelos de instrução escolar tradicionais, produzindo argumentos acerca de uma ampliação dos papéis sociais da escola (SIMONS; MASSCHELEIN, 2006; BALL; MAINARDES, 2011).

Tais argumentos, para além de sua integração às pautas políticas internacionais, enraizaram-se nas diferentes políticas de escolarização mobilizadas pelo Estado brasileiro. Uma das decorrências amplamente estudadas nesse processo, refere-se a 
uma visão minimalista das políticas curriculares, considerando, por exemplo, que não mais falemos em "necessidades básicas", optando pela expressão "necessidades mínimas"2. Acerca disso, seguindo sua argumentação faz-se possível observar que a educação escolar foi reduzida a "objetivos de aprendizagem observáveis, mediante formulação de padrões de rendimento (expressas em competências) como critérios da avaliação de larga escala" (LIBÂNEO, 2012, p. 19).

A naturalização dessa compreensão do processo e das políticas de escolarização no Brasil conduziram, ainda segundo Libâneo, à promoção de um conjunto de novas características para a escola:

a) conteúdos de aprendizagem entendidos como competências e habilidades mínimas para a sobrevivência e o trabalho (como um kit de habilidades para a vida); b) avaliação do rendimento escolar por meio de indicadores de caráter quantitativo, ou seja, independentemente de processos de aprendizagem e formas de aprender; c) aprendizagem de valores e atitudes requeridos pela nova cidadania (ênfase na sociabilidade pela vivência de ideais de solidariedade e participação no cotidiano escolar) (LIBÂNEO, 2012, p. 20).

Nessa direção, é fundamental destacar que a análise conduz à perspectiva de que a escola pública de nosso País foi reduzida aos "mínimos" elementos da convivência social e aos mecanismos de diferenciação pedagógica. Libâneo é mais incisivo ao argumentar que, sob a face humanista desse novo modelo, emergiu uma instituição escolar "caracterizada por suas missões assistencial e acolhedora" (2012, p. 23), ocorrendo "uma inversão das funções da escola: o direito ao conhecimento e à aprendizagem é substituído pelas aprendizagens mínimas para a sobrevivência" (2012, p. 23). Essa instituição, assim caracterizada, ampliou o dualismo da escola pública brasileira.

Outras pesquisas brasileiras no campo educacional, de perspectivas teóricas diferentes, encontraram-se com resultados semelhantes (MIRANDA, 2005; MOREIRA, 2007; FABRIS, 2007; FABRIS, TRAVERSINI, 2011, CAVALIERE, 2007). Em geral, tais estudos são realizados em contextos diferentes, analisam objetos variados com teorizações divergentes, mas conseguem encaminhar análises de acordo com essa mesma tendência nas políticas contemporâneas

A crítica das expectativas de aprendizagem, bem como seus impactos na constituição do trabalho docente, encontramos em Oliveira (2011). 
de escolarização em curso no Brasil. Nota-se um deslocamento nas pautas pedagógicas da última década.

Em um texto produzido há quase uma década, Marília Gouvêa de Miranda (2005), ao analisar as políticas públicas destinadas à organização do ensino em ciclos de formação, assinalava que a escola produzida pelo "princípio do conhecimento" estava sendo substituída por uma escola dirigida pelo "princípio da socialidade". A autora utilizava o termo "socialidade" referindo-se ao fato de que "a escola organizada em ciclos se situa como um tempo/espaço destinado à convivência dos alunos" (MIRANDA, 2005, p. 641). Sua pesquisa encaminha para a perspectiva de que o próprio conceito de escola é modificado.

Isso implica mudar o conceito de escola ou, o que dá no mesmo, a noção de socialização mediada pela escola, que deixa de ser orientada por um critério, digamos iluminista, de que a emancipação dos indivíduos deva ocorrer mediante a aquisição de conhecimentos, saberes, técnicas e valores que lhes permitam viver em uma sociedade mediada por esses conhecimentos, saberes, técnicas e valores, passando a orientarem-se por uma noção de socialidade que prescinde da mediação do conhecimento como sua dimensão fundamental, sendo a socialidade per si o seu critério. O importante é que os alunos permaneçam na escola, disponham de tempo e de espaço para que possam desfrutar o que ela possa lhes oferecer, inclusive a oportunidade de adquirir conhecimentos, mas não apenas isso ou não fundamentalmente isso: que eles possam viver ali e agora uma experiência de cidadania, de convivência, de formação de valores sociais (MIRANDA, 2005, p. 642-643).

Essa ressignificação do papel da escola também perpassou as conclusões de outras importantes investigações na área. Fabris e Traversini (2011), ao estudarem escolas situadas em periferias do sul do Brasil, destacam que a escola tem assumido como sua principal ação a busca pela proteção e pela segurança social, fazendo com que os conhecimentos sejam secundarizados na formação dos sujeitos escolares daquele contexto. De outra forma, Moreira ${ }^{3}$ (2007) tem defendido que, ainda que a criança e a sua cultura sejam indispensáveis para a vida escolar, é importante atribuir centralidade, no estudo e no planejamento das políticas de currículo, ao conhecimento escolar. Insisto no sentido de que a eles se associe uma aguda preocupação com o conhecimento, com sua aquisição,

Os estudos de Moreira $(2007 ; 2009 ; 2010)$ têm assumido a perspectiva de que os currículos escolares podem ser conceituados como o conjunto de experiências escolares que se desdobram em torno do conhecimento escolar. 
com uma instrução ativa e efetiva, com um professor ativo e efetivo, que bem conheça, escolha, organize e ensine os conteúdos de sua disciplina ou área do conhecimento (MOREIRA, 2007, p. 37).

Cavaliere (2007), ao examinar as relações entre tempo de escola e qualidade na educação pública, considera o caráter democrático das propostas de ampliação do tempo escolar, visto que busca reduzir as desigualdades entre os sistemas escolares. Entretanto, segundo a pesquisadora, "a novidade da ampliação do tempo diário estaria na transformação do tipo de vivência escolar, na mudança, portanto, no papel desempenhado pela escola" (CAVALIERE, 2007, p. 1021). Do ponto de vista pedagógico, sugere que a ampliação do tempo escolar somente faz sentido na medida em que qualificar as experiências escolares dos diferentes estudantes, pois "toda e qualquer escola sempre atua, ou pretende atuar, para além da instrução escolar" (CAVALIERE, 2007, p. 1021).

Após estabelecer um conjunto de investigações durante a última década, Cavaliere diagnosticou algumas concepções de escola em tempo integral, diluídas nas diferentes propostas em andamento no Brasil. A autora apresenta que a visão ainda predominante tem um caráter assistencialista, pois privilegia $\mathrm{o}$ atendimento social às crianças pobres.

[...] Vê a escola de tempo integral como uma escola para os desprivilegiados, que deve suprir deficiências gerais da formação dos alunos; uma escola que substitui a família e onde o mais relevante não é o conhecimento e sim a ocupação do tempo e a socialização primária. Com frequência, utiliza-se o termo "atendimento". A escola não é o lugar do saber, do aprendizado, da cultura, mas um lugar onde as crianças das classes populares serão "atendidas" de forma semelhante aos "doentes" (CAVALIERE, 2007, p. 1028-1029).

A reflexão oferecida por Cavaliere aproxima-se bastante das considerações investigativas acima descritas, visto que também consegue notar novos delineamentos para as funções sociais das instituições escolares. A lógica de uma "escola para o atendimento" tende a fragilizar o lugar ocupado pelo conhecimento, pela aprendizagem e pela transmissão cultural na escola pública brasileira de nosso tempo. Conforme observaremos a seguir, essa perspectiva também pode ser observada nas políticas de constituição do conhecimento escolar descritas pela literatura internacional.

Ao examinarmos a literatura internacional sobre o campo, observamos que esta articula-se com a demanda de retomarmos o conhecimento escolar como 
objeto de estudo curricular (MOREIRA, 2007). Internacionalmente, autores como Young $(2007 ; 2010 ; 2011)$, Müller (2000; 2003), Popkewitz (2009; 2010), Dussel (2009), Nóvoa (2009), Yates e Collins (2012), Finocchio (2010) e Charlot (2009), de perspectivas teóricas diferentes, têm apontado a necessidade de retomarmos investigações acerca da produção do conhecimento escolar ${ }^{4}$, visto que, possivelmente, as atuais políticas de currículo "dizem muito pouco sobre o papel do próprio conhecimento na educação" (YOUNG, 2011, p. 395). Segundo esses autores, o lugar ocupado pelo conhecimento escolar nas reformas contemporâneas de escolarização evidencia um amplo deslocamento das funções sociais da instituição escolar. Tal deslocamento conduziria a uma ressignificação das políticas de produção do conhecimento escolar (YOUNG, 2007).

$\mathrm{Na}$ esteira dessa argumentação, é possível inferir que as instituições escolares não podem ficar circunscritas somente ao que interessa ao seu público, mas apresentar condições críticas para conduzi-los, pedagogicamente, a um modo de vida democrático. Que condições culturais, políticas e econômicas permitem a emergência de novas configurações escolares? Quais deslocamentos pedagógicos permitem a consolidação de mudanças nas culturas escolares que tendem a secundarizar a transmissão cultural e, ao mesmo tempo, delinear novas perspectivas para o conhecimento escolar? Como forma de explorar essas problematizações, na seção a seguir posicionaremos essas questões sob as descrições contemporâneas acerca do conceito de cultura do novo capitalismo, desenvolvido pelo sociólogo Sennett (2006).

\section{Novo capitalismo, meritocracia e escolarização: elementos para um diagnóstico}

No transcorrer das últimas décadas, a partir de um conjunto de mudanças sociais, políticas e econômicas, as relações entre educação e cultura têm sido ressignificadas. A emergência de questões como a globalização, os multiculturalismos, as pautas sociais ligadas à preservação ambiental ou à proteção social, conduziram a novos delineamentos produzidos no interior das políticas de escolarização. Com as condições daquilo que Sennett (2006) nomeou como "cultura do novo capitalismo", outros mecanismos de regulação ingressaram fortemente na composição das políticas e práticas escolares.

Pelo menos desde a década de 1990, pesquisadores internacionais como Popkewitz (2009), Dale (2004), Robertson (2012) ou Ball (2009), para ficarmos circunscritos somente ao mundo anglófono, anunciaram-nos os modos pelos quais as reformas

4 Em um exercício de revisão dos estudos produzidos na América Latina, a pesquisadora argentina Silvia Finocchio (2010) constatou que um dos temas menos trabalhados na última década foi a questão dos saberes escolares. 
dos sistemas de ensino, colocadas em ação pelas políticas neoliberais, operavam na condução da vida social dos indivíduos. Popkewitz (2000) destacava o quanto tais reformas das políticas de escolarização apresentavam-se como práticas de "administração social" (p. 141), práticas estas que procuravam reconstituir a individualidade e a liberdade dos sujeitos. O estudioso estadunidense, ao evidenciar as articulações entre administração social e liberdade, destacava que tal cenário político era acompanhado por concepções de história, cultura e sociedade que objetivavam converter "o indivíduo em alguém capaz de agir com um certo senso de responsabilidade e com aparente autonomia" (POPKEWITZ, 2000, p. 142).

Nessa direção, precisamos destacar que a administração social dos indivíduos e as políticas de escolarização, tanto no que se refere aos currículos escolares, quanto às práticas profissionais dos professores, apresentavam-se articuladas aos dispositivos políticos de atuação do Estado Moderno, ao mesmo tempo em que interagiam com as condições sociais e econômicas do seu tempo histórico. Os múltiplos tensionamentos existentes na relação entre educação e sociedade, entre métodos de ensino e conteúdos a serem ensinados, entre currículos escolares e práticas docentes, atravessam a histórica produção das culturas escolares. Desde o nascimento do discurso pedagógico, em diferentes tempos e lugares, o lugar de definição das práticas de ensino vem sendo modificado. Desde as corporações de ofício, passando pelas universidades medievais, até a contemporaneidade, o monopólio de definição do que deveria ser traduzido em prática escolar vem recebendo novos agenciamentos, inserindo-se em diferenciadas redes de poder e de saber. Em decorrência disso, faz-se possível afirmar que as próprias concepções de estudante, professor ou instituição escolar receberam variações no interior desta trama histórica.

Vale apontar que, desde a consolidação da Modernidade Pedagógica, podemos situar o Estado como a instância que atribuía aos pressupostos pedagógicos o respaldo necessário para sua atuação (NARODOWSKI; BRAILOVSKI, 2006). Assim, dessa aproximação entre Pedagogia e Estado Moderno, fez-se possível notar uma conotação urbanizadora e civilizadora aos incipientes sistemas escolares estatais. Tanto na Europa, quanto na América Latina, o final do século XIX foi marcado pela emergência de um processo de consolidação da função educadora dos Estados (CAMBI, 1999; NARODOWSKI; BRAILOVSKI, 2006), fato esse decorrente tanto de sua capacidade financiadora, quanto de seus novos desafios ligados ao controle estatal de suas populações.

A partir dessas condições, a escola moderna e suas promessas são reposicionadas desde as disposições e capacidades do Estado Moderno. Segundo Narodowski 
e Brailovski (2006), essa aproximação articulada ocorria não apenas pelas condições de financiamento do Estado, mas também pela sua capacidade pública de "legitimar uma utopia e de produzir processos massivos de disciplinamento escolar com fortes efeitos homogeneizadores e universalizantes" (p. 65). A escola pública, pelo menos no Ocidente, emergiu como uma ferramenta de Estado destinada a publicizar o ideário de uma nação, delinear os vínculos identitários de seus frequentadores e projetar crenças e valores para o futuro. A urbanidade, e sua materialização nas reformas das cidades do século XVIII e XIX, tornou-se um dos grandes ideais da educação financiada pelo Estado. O estar e o viver nas cidades - a formação de cidadãos - efetivou-se como uma das grandes metanarrativas pedagógicas da Modernidade, ideário que ainda sustenta as pedagogias do nosso tempo (CAMBI, 1999).

Entretanto, o século XXI tem nos apresentado um conjunto significativo de transformações sociais, mudanças essas que produziram fortes ressonâncias nos modos pelos quais nos constituímos como sujeitos. Diferentes pensadores sociais têm procurado destacar alguns aspectos dessa questão. Bauman (2003), por exemplo, assinala que a Modernidade da qual experienciamos é cada vez mais líquida, marcada por valores instáveis e transitórios. Sloterdjik (2005) sugere que estamos vivenciando modos diferenciados de nos constituirmos como indivíduos. Estaríamos ingressando em um cenário de "individualismo do autodesenho", no qual o objetivo é converter-se, esteticamente, em um objeto original e criativo, promovendo ações permanentes para o desenvolvimento de suas próprias capacidades. O sociólogo Sennett (2006), o qual ampliaremos sua abordagem a seguir, assinala que estamos ingressando em uma cultura do novo capitalismo, marcada por processos de subjetivação ligados à flexibilidade, ao curto prazo e à multirreferencialidade. Destaca ainda que tais cenários são caracterizados pela meritocracia, secundarizando os processos de trabalho e de educação caracterizados pela perícia. Em um rápido exercício de diagnóstico do nosso tempo, podemos inferir que estamos nos movimentando em um tempo transitório, inseridos em relações de trabalho e estudo meritocráticas, no qual os sujeitos investem permanentemente em seu "autodesenho". Ampliaremos, neste momento, a abordagem de Richard Sennett.

Diferentemente do período caracterizado como capitalismo industrial, sustentado pela consolidação do modelo de Estado de Bem-estar social, as condições econômicas do capitalismo contemporâneo têm produzido novos delineamentos para a vida social. No que se refere à subjetividade e às condições de trabalho dos sujeitos, o sociólogo Sennett (2006) argumenta que uma das principais ameaças à constituição destes sujeitos trata-se do "fantasma da inutilidade". Ao contrário do capitalismo industrial em que os trabalhadores organizavam suas carreiras em planejamentos a longo prazo, a volatilidade e a flexibilidade marcam as 
novas condições produtivas. Processos como a oferta global de mão de obra, a automação e a gestão do envelhecimento são algumas das características descritas pelo sociólogo para esse período.

Sob a égide do fantasma da inutilidade, uma nova gramática formativa passou a conduzir os debates acerca das relações entre educação e trabalho, da mesma forma que proliferaram novas estratégias para a gestão dos recursos humanos. "Nessa investida, passou-se a definir 'capacitação' como a capacidade de fazer algo novo, em vez de depender do que já se havia aprendido" (SENNETT, 2006, p. 93-94). Sob as condições de uma sociedade das capacitações, os sujeitos passam a investir permanentemente em sua formação, as empresas modificam-se na busca de novas condições e emerge a gramática pedagógica da aprendizagem ao longo da vida ${ }^{5}$, fazendo com que as instituições educativas apregoem modelos de formação continuada. Capacitar-se a todo momento para um mundo produtivo em permanente mudança apresenta-se como um novo imperativo pedagógico. Entretanto, para a análise da constituição desse novo imperativo, alguns deslocamentos podem ser visibilizados.

Os processos formativos do capitalismo industrial alicerçavam-se na concepção de perícia. Adquirir perícia representava compreender todas as etapas de um determinado trabalho, fosse ele a escrita de um texto, a realização de um cálculo ou a fabricação de um relógio. Sennett argumenta que "uma definição abrangente de perícia seria: fazer algo bem-feito simplesmente por fazer" (2006, p. 98). Os processos de formação humana eram constituídos pelas ideias de autodisciplina e autocrítica, visto que fazer algo bem-feito tinha sua própria importância. "A mestria tem o seu valor, numa medida que é ao mesmo tempo concreta e impessoal: o que é bem-feito é bem-feito" (p. 99). Conforme a descrição do sociólogo, a perícia demarcou os processos de trabalho e de formação humana ao longo de toda a consolidação do capitalismo industrial; porém, com a emergência do capitalismo contemporâneo um novo conceito passa a reger esses processos: a meritocracia.

Vista desta maneira, a perícia não parece ter muito a ver com as instituições do capitalismo flexível. O problema está na última parte de nossa definição - fazer alguma coisa simplesmente por fazer. Quanto mais sabemos como fazer alguma coisa bem-feita, mais nos preocupamos com ela. Todavia, as instituições baseadas em transações de curto prazo e tarefas que estão constantemente sendo alteradas não propiciam esse aprofundamento (SENNETT, 2006, p. 99-100).

O sociólogo português Licínio Lima (2012) argumenta que, sob essas condições, podemos observar uma "subordinação da educação e do conhecimento a objetivos predominantemente instrumentais de promoção da rivalidade, no contexto da agora denominada 'sociedade da aprendizagem e do conhecimento'"' (p. 9). 
Em uma sociedade marcada pelas capacitações permanentes, a perícia apresenta-se como um problema na medida em que o importante é não "ficar travado". Ficar travado, nesse cenário, implica em ficar demasiadamente arraigado ao domínio de uma técnica ou de uma área de trabalho. O capitalismo contemporâneo expõe uma nova condição para a vida produtiva (com fortes ressonâncias para a formação humana), a saber: "a equiparação do talento com o mérito" (SENNETT, 2006, p. 102). A perícia privilegiava as relações de domínio da técnica, nas quais o talento representava um tipo de prestígio moral. "Mas agora o talento servia para medir um novo tipo de desigualdade social: algo que fosse criativo ou inteligente significava para os outros superior, referindo-se a uma pessoa de maior valor" (p. 102).

O deslocamento acima descrito, da perícia para a meritocracia, produz significativas implicações para o campo educacional, em geral, e para os Estudos Curriculares, em particular. Não são recentes os estudos que apontam mudanças dos conhecimentos ensinados nos processos de escolarização (conforme explicitamos na seção anterior). O deslocamento da perícia para a meritocracia é o modo pelo qual optamos realizar a descrição do contexto de produção das atuais políticas curriculares, tanto no Brasil, quanto internacionalmente. Criatividade, produtividade, oportunidade, eficiência, protagonismo, livre escolha ${ }^{6}$ são algumas das expressões que se proliferam na gramática pedagógica mobilizada no início do século XXI. Não se constitui em novidade retomar os modos pelos quais a referida gramática é gestada em determinadas organizações internacionais, como a Unesco, o Banco Mundial, a OCDE, dentre outros ${ }^{7}$. Um exemplo disso podemos encontrar em um documento publicado pela Unesco em 2005 (traduzido no Brasil em 2008), nomeado como "Reforma da educação secundária: rumo à convergência entre a aquisição de conhecimento e o desenvolvimento de habilidade". Ao definir quais seriam os novos conceitos delineadores na formação a nível secundário, o documento é bastante enfático como evidencia o excerto a seguir:

A fim de ajudar os jovens a enfrentar eficazmente esses desafios, sejam eles positivos ou negativos, os sistemas de educação secundária precisam concentrar-se em conferir aos jovens a capacidade de desenvolver personalidades produtivas, responsáveis, bem equipadas para a vida e para o trabalho na atual sociedade do conhecimento baseada em tecnologia. É claro que, para que os indivíduos logrem

\footnotetext{
Estudamos recentemente os modos como a questão do empreendedorismo, por exemplo, tem perpassado a produção as agendas pedagógicas contemporâneas, seja nas relações entre trabalho e educação, seja na emergência dos saberes tecnocientíficos nos currículos escolares.

7 São exemplares desse tipo de abordagem estudos como os de Ball (2009) e de Popkewitz (2009), com grande repercussão no Brasil e internacionalmente.
} 
ajustar-se e competir no ambiente em rápida evolução que caracteriza o mundo contemporâneo, necessitam de um repertório de habilidades para a vida que inclui, entre outras, habilidades analíticas e de resolução de problemas, criatividade, flexibilidade, mobilidade e empreendedorismo (UNESCO, 2008, p. 10).

Sob tais condições, "as ideias pedagógicas de autonomia, criatividade e independência, uma vez plenamente desenvolvidas correm o risco de nos converter em escravos de nossa autonomia" (DUSSEL, 2009, p. 358). Obviamente que tais imperativos pedagógicos não são tomados na íntegra em sua aproximação com as políticas curriculares no Brasil. Como nos têm apontado os estudos de Lopes e Macedo (2011), influenciadas pelo conceito bernsteiniano de recontextualização, faz-se preciso "entender as modificações discursivas pela circulação de textos nos diferentes contextos sociais, para além dos processos de produção e reprodução nas salas de aula" (LOPES; MACEDO, 2011, p. 106). Cabe reiterar que, conforme argumentamos até esse momento, interessa-nos problematizar a questão do conhecimento escolar em propostas curriculares alternativas, tendo a cultura do novo capitalismo como contexto de emergência dos delineamentos contemporâneos. A ampliação da jornada escolar para o Ensino Médio é o nosso foco, conforme apresentaremos a seguir alguns delineamentos empíricos para o presente estudo.

\section{Objeto de pesquisa e primeiras impressões empíricas}

Considerando as condições políticas e econômicas da globalização e as modificações no capitalismo contemporâneo, descritas na seção anterior, inúmeras publicações internacionais têm tomado como alvo o período equivalente ao Ensino Médio. Tais documentos sugerem que a exclusiva preparação para estudos posteriores, no caso brasileiro a preparação para o vestibular, constitui-se como um objetivo frágil, em razão da grande evasão escolar característica desta etapa da escolarização, ou mesmo pelas poucas articulações com o mundo do trabalho e às inovações tecnocientíficas. Dentre os inúmeros organismos internacionais preocupados em estabelecer diretrizes para essa questão, conforme assinalamos anteriormente, destaca-se ao longo da última década a atuação da Unesco.

A América Latina tem sido objeto de um conjunto de estudos da referida organização internacional, em geral indicando as fragilidades dos modelos curriculares implementados. No ano de 2008, a Unesco publicou no Brasil o documento Reforma da Educação Secundária, publicado originalmente na Europa em 2005, objetivando estabelecer um mapeamento das principais tendências contemporâneas nas políticas de educação secundária em seus países-membros. 
Toma como público privilegiado os planejadores de políticas educacionais nos países que continuamente revisam seus sistemas de ensino, oferecendo subsídios e modalidades de organização curricular para serem adaptados de acordo com suas demandas sociais e econômicas. Do ponto de vista pedagógico, parte do pressuposto de que todo sistema de ensino que prepara exclusivamente para o ensino superior é "brutalmente ineficaz".

Considerando o cenário internacional de globalização e de transformações tecnológicas, no qual a subjetividade dos estudantes é modificada permanentemente, o documento sugere que "os sistemas de educação secundária precisam concentrar-se em conferir aos jovens a capacidade de desenvolver personalidades produtivas, responsáveis, bem equipadas para a vida e para o trabalho na atual sociedade do conhecimento baseada na tecnologia" (UNESCO, 2008, p. 11). Para promover a formação de personalidades produtivas, o documento encaminha que as experiências escolares devam fomentar habilidades analíticas e de resolução de problemas. Questões como a criatividade, a flexibilidade e o empreendedorismo passam a ser recomendadas como pressupostos básicos para a educação secundária na referida sociedade do conhecimento. Nessa lógica organizativa, que hoje perfaz as políticas curriculares de boa parte dos países filiados a Unesco, a histórica dicotomitização entre ensino propedêutico ou profissional na formação juvenil não faz mais sentido, visto que tal processo orienta-se por "competências essenciais genéricas".

Os desdobramentos curriculares dessa abordagem para a educação secundária delineiam a centralidade de competências essenciais (letramento e numerização) e competências transversais. Encaminham a consolidação de modelos curriculares diversificados e flexíveis que se adaptem aos diferentes contextos e às diferentes personalidades. Entretanto, enaltece que "as políticas relativas à educação secundária devem ser objeto de contínuo exame e devem ser constantemente atualizadas para que possam continuar a progredir ao ritmo das transformações científicas, econômicas e sociais" (UNESCO, 2008, p. 22). Em síntese, a nomeada formação de personalidades produtivas na educação secundária é apresentada como um objetivo prioritário para a educação no século XXI. A criatividade, a resolução de problemas e o trabalho em equipe são indicados como as chaves da nova organização curricular, na medida em que "a ênfase deverá ser posta no conhecimento de como utilizar essas ferramentas para investigar e tratar rapidamente uma quantidade de conhecimentos crescentes, mais do que a simples aquisição de conhecimentos propriamente ditos" (UNESCO, 2008, p. 23).

Em articulação a esses estudos, a Representação da Unesco no Brasil desenvolveu um projeto intitulado "Currículos de Ensino Médio", considerando como finalidade 
a proposição de "protótipos curriculares viáveis para a integração entre a educação geral, a educação básica para o trabalho e a educação profissional no ensino médio" (UNESCO, 2011, p. 6). O produto final deste estudo foi publicado no País, em maio de 2011, com o título "Protótipos curriculares de Ensino Médio e Ensino Médio integrado: resumo executivo".

O referido texto propõe dois protótipos. O primeiro aponta um currículo focado para o mundo do trabalho e as práticas sociais, "desenhado para garantir aprendizagens necessárias ao desenvolvimento de conhecimentos, atitudes, valores e capacidades básicas para o exercício de todo e qualquer tipo de trabalho" (UNESCO, 2011, p. 6). Em decorrência desse protótipo é apresentado um segundo tipo que busca integrar o Ensino Médio com as diferentes formas organizativas da educação profissional. Ambos os modelos apresentados pelo documento examinado são justificados pela necessidade de atendimento das condições da sociedade e da juventude do País. Em outras palavras, "a preparação simultânea do jovem para o mundo do trabalho e a prática social e a continuidade de estudos conjuga os objetivos de interesse nacional com os interesses do público específico" (UNESCO, 2011, p. 7).

Intencionando articular os interesses juvenis com a gramática dos "interesses nacionais", o documento atribui bastante ênfase para o entendimento dos protótipos enquanto "referências". Objetiva orientar um processo de reforma dos currículos escolares brasileiros. Pretende atender tanto às demandas juvenis, quanto às demandas econômicas e políticas para o desenvolvimento nacional. Em articulação a essa perspectiva, o currículo é posicionado como um conjunto de oportunidades de aprendizagem. A gramática das oportunidades pode ser lida como característica dos desenvolvimentos contemporâneos do neoliberalismo americano, no qual uma sociedade livre é aquela que multiplica oportunidades para todos os cidadãos (BALL, 2010).

Do ponto de vista pedagógico, os Protótipos Curriculares apontam como base de seus princípios orientadores a formação integral do estudante. "Eles consideram que a continuidade de estudos e a preparação para vida, o exercício da cidadania e o trabalho são demandas dos jovens e finalidades do ensino médio" (UNESCO, 2011, p. 8). Em consonância a isso, supõem que toda atividade curricular terá como centro o desenvolvimento integral do estudante, sobretudo no que se refere a "intervenções transformadoras" na realidade em que o sujeito está inserido.

Considerar o Ensino Médio como uma comunidade de aprendizagem é a principal proposição curricular do documento. Ainda que postule a interdisciplinaridade, a contextualização e a produção do currículo por meio de projetos, ou mesmo que 
sugira a ampliação da carga horária para três mil horas com ampla flexibilização de carga horária, a produção de uma comunidade de aprendentes é o desafio posto. Diante disso, é feita uma opção metodológica fundamental, a saber: a valorização "das formas didáticas que privilegiam a atividade do estudante no desenvolvimento de suas capacidades e na construção do seu conhecimento" (UNESCO, 2011, p. 14). Projetos e ações investigativas que desencadeiem o protagonismo dos estudantes apresentam-se, no documento examinado, como importante imperativo metodológico.

\section{Ampliação da jornada escolar nas políticas curriculares para o Ensino Médio}

Para o desenvolvimento deste estudo, partimos do pressuposto de que os estudos sobre os currículos escolares, em contextos de reforma, ainda apresentam intensa potencialidade analítica (MOREIRA, 2010; PACHECO, 2003). Tal dimensionamento mostra-se relevante em nosso tempo, dentre outros motivos, na medida em que diferentes formas de pensamento curricular assentam-se em "uma tese educacionista que atribui à educação o desenvolvimento nacional e global, o progresso individual e social dos indivíduos, a solução dos conflitos étnicos, religiosos ou ideológicos, assim como as diferenças socioeconômicas" (DIAZ-BARRIGA, 2013, p. 352). Em outra direção, partimos de uma perspectiva teórico-metodológica que escapa da possibilidade de posicionar a escola como "um tipo de agência de entregas, que deve se concentrar em resultados e prestar pouca atenção ao processo ou ao conteúdo do que é entregue" (YOUNG, 2007, p. 1291). Assim sendo, conforme sublinhamos anteriormente, estruturamos nossa abordagem investigativa atribuindo centralidade ao conhecimento escolar enquanto objeto privilegiado de análise (GABRIEL; CASTRO, 2013; MOREIRA, 2013; SILVA; PEREIRA, 2013).

Para este estudo, em particular, estruturamos metodologicamente o presente estudo em três etapas articuladas. Na primeira etapa, inicialmente realizamos uma revisão da literatura da temática do estudo (SILVA; PEREIRA, 2013). Buscamos em diferentes bases de dados brasileiras sistematizar as principais tendências teóricas e empíricas para o tratamento analítico das políticas do conhecimento escolar. Ao mesmo tempo, desencadeamos uma revisão conceitual da temática em diferentes tradições investigativas dos Estudos Curriculares. Ao final desta etapa concluímos que as pesquisas sobre o conhecimento escolar em nosso País, ainda que apresentem significativa densidade teórica, ainda estruturam-se a partir de poucos estudos empíricos (SILVA; PEREIRA, 2013).

$\mathrm{Na}$ segunda etapa prevista para esta movimentação investigativa, a qual apresentamos no presente artigo, realizamos uma análise documental dos principais 
textos curriculares que ordenaram as práticas curriculares do Ensino Médio no referido contexto investigativo. Tomando como base esse levantamento, efetuamos a seleção dos documentos a serem investigados. Para a seleção trabalhamos com os seguintes critérios: a) etapa da educação básica a que se destina; b) período de publicação; c) repercussão nas políticas de currículo do Ensino Médio do Estado; d) articulação aos documentos publicados pelo Ministério da Educação e pelos organismos internacionais. Após a mobilização desses critérios, selecionamos o corpus documental mostrado na Tabela.

Ao final, na terceira fase (ainda em andamento), estamos produzindo um conjunto de inserções empíricas em três escolas públicas estaduais, reguladas por práticas curriculares diferenciadas, fazendo uso de entrevistas com gestores escolares, visitas a escolas e análises de projetos escolares. Para a composição investigativa proposta serão examinados os seguintes aspectos: concepções de conhecimento escolar, sistemas de raciocínio pedagógicos mobilizados, modalidades de organização das práticas escolares e relações entre políticas públicas e escolarização.

No desenvolvimento de suas políticas curriculares para o Ensino Médio, o Estado do Rio Grande do Sul tem desenvolvido nos últimos anos um conjunto de reformas curriculares que objetivam qualificar as experiências pedagógicas dos estudantes do Ensino Médio. Propomo-nos a examinar criticamente as propostas curriculares que estabelecem a ampliação da jornada escolar. Assim, optamos pelo acompanhamento de práticas escolares vinculadas a três programas curriculares em desenvolvimento no referido contexto, a saber: a) a experiência dos CIEP's, desenvolvida de forma ininterrupta no Rio Grande do Sul desde o ano de 1990, e sua lógica de formação em tempo integral; b) a implementação do Programa Ensino Médio Inovador, do Ministério da Educação, na qual o referido Estado aderiu no segundo semestre de 2011; c) a reforma curricular intitulada Ensino Médio Politécnico, política curricular desenvolvida desde o

Tabela. Documentos selecionados para a análise.

\begin{tabular}{lcc}
\hline Título do documento & Ano & $\begin{array}{c}\text { Contexto de } \\
\text { elaboração }\end{array}$ \\
\hline Protótipos curriculares de Ensino Médio e Ensino Médio Integrado & 2011 & Unesco \\
Reforma da educação secundária & 2008 & Unesco \\
A ciência para o século XXI & 2003 & Unesco \\
Diretrizes curriculares nacionais para a EB & 2010 & Brasil \\
Diretrizes curriculares nacionais para o EM & 2012 & Brasil \\
Ensino Médio Politécnico & 2011 & Rio Grande do Sul \\
Ensino Médio Politécnico: síntese da proposta & 2012 & Rio Grande do Sul \\
EMP: perguntas e respostas & 2012 & Rio Grande do Sul \\
\hline
\end{tabular}

Fonte: Pesquisa do autor. 
início do ano de 2011. Assim, problematizaremos a questão do conhecimento escolar a partir do exame de três experiências diferentes desenvolvidas no mesmo contexto.

\section{Escolas de jornada ampliada: promoção de pedagogias de proteção}

A primeira concepção de conhecimento escolar que, de certa forma, perpassa também as demais, refere-se à perspectiva de ampliar a jornada escolar com vistas a garantir a proteção social para os jovens. Ao entender-se que o mundo social torna-se cada vez mais perigoso, as políticas curriculares destinadas aos jovens buscam intervir na regulação dos riscos e perigos que podem atingir o referido público. Isso implica em reconhecer a promoção de "pedagogias de proteção", isto é, estratégias pedagógicas focadas no gerenciamento das vulnerabilidades sociais. Particularmente no Estado do Rio Grande do Sul, no início da década de 1990, observamos a emergência de um conjunto de iniciativas de criação de escolas de tempo integral. Sob a gestão do trabalhista Alceu Collares (1991-1995), foram criados no Estado noventa e quatro Centros Integrados de Educação Pública (CIEP's), sob inspiração dos modelos produzidos no Rio de Janeiro sob a concepção de Leonel Brizola e Darcy Ribeiro. Os referidos centros eram concebidos enquanto estratégias políticas de educação em tempo integral, espaços nos quais os sujeitos escolares permaneceriam em dois turnos escolares, recebendo aspectos tanto da educação formal, como se nomeava na época, quanto da educação informal, que corresponderia aos demais cuidados pedagógicos como a alimentação, atendimento odontológico, projetos comunitários, formação complementar, dentre outros.

O desafio posto, nessa gramática política, era construir escolas de qualidade em bairros pobres objetivando, conforme um discurso do governador Alceu Colares, "conscientizar que a escola de tempo integral é essencial para a educação com qualidade. Sem ela, jamais conseguiremos competir com os demais países" ${ }^{8 "}$. Entendia-se que a melhor forma de educar as crianças das comunidades populares era ampliar seu tempo de permanência na escola, perspectiva essa que colaboraria tanto para a formação intelectual desses sujeitos, quanto para o desenvolvimento do País. Esse argumento inspirava-se no diagnóstico produzido por Darcy Ribeiro, na segunda metade da década de 1980, no qual indicava a incapacidade dos brasileiros para a educação de sua população (MAURÍCIO, 2004). Nessa direção, caberia às escolas considerar como princípio orientador "o respeito ao universo cultural do aluno no processo de introdução da criança no domínio do

8 COLLARES, A. Os CIEPs do Rio Grande do Sul. Brasília, DF: PDT; 2010. Disponível em: <http://www.pdt.org. $\mathrm{br} /$ index.php/nossas-bandeiras/educacao/mais-sobre-os-cieps/os-cieps-do-rio-grande-do-sul>. Acesso em: 18 jun 2013. 
código culto. A escola devia servir de ponte entre a cultura do aluno, que sabe muitas coisas para garantir sua sobrevivência, e o conhecimento formal exigido pela sociedade" (MAURÍCIO, 2004, p. 41).

Ainda que a pauta dessa política de escolarização fosse ampla e diversificada, foram inúmeras as críticas advindas sobre essa abordagem. Bomeny (2007) sugere que o programa dos CIEP'S, no Rio de Janeiro, produziu inúmeras descontinuidades em sua implementação, tanto no que se refere ao modelo de liderança populista e personalista de Leonel Brizola, quanto pela pauta messiânica do projeto que presumia um "salvar pela escola". Cavaliere (2007) reconhece os CIEP's como a experiência mais duradoura em educação de tempo integral na história recente de nosso País, entretanto, descreve que, nas experiências da cidade do Rio de Janeiro, pode ser observado um efeito paradoxal do tempo, uma vez que "a ocupação pouco interessante do horário integral, levou à criação de um conceito negativo sobre essas escolas e ao seu consequente esvaziamento" (CAVALIERE, 2007, p. 1019). Por outro lado, examinando especificamente uma experiência de Centro Integrado de Educação Pública desenvolvida no interior do Rio Grande do Sul, Castro et al. (2011) comentam dimensões exitosas da qualidade pedagógica do trabalho desenvolvido nessa instituição escolar, sobretudo pelas relações políticas desenvolvidas, descritas como "uma escola em que a participação faz a diferença".

Ainda que seja uma política de escolarização de mais de duas décadas, a proposta dos CIEP's manteve-se na agenda educacional do Estado do Rio Grande do Sul. Mesmo reduzida em inúmeros governos estaduais, essa perspectiva organizativa segue atendendo à Educação Básica e produzindo repercussões curriculares importantes para examinarmos a questão do conhecimento escolar em propostas curriculares alternativas para o Ensino Médio. Notamos aqui a predominância de uma concepção de conhecimento escolar preocupada em mobilizar saberes e práticas escolares que colaborem para a intervenção imediata dos indivíduos em suas ações comunitárias. Isso pode ser evidenciado, em um plano sociológico mais amplo, naquilo que Bauman (2013) sugere como "privatização" das responsabilidades do Estado Social.

Com a crise dos arranjos políticos do Estado Social, configura-se a constituição de um processo de construção comunitária, alicerçada na "promoção dos padrões individualizantes, em essência anticomunais, do estilo do mercado de consumo, padrões que colocam os indivíduos em competição entre si” (BAUMAN, 2013, p. 24-25). Na medida em que o Estado não mais garante os seguros coletivos, percebe-se que "o espectro da autonomia individual está se expandindo, mas também arcando com o peso de funções antes consideradas de responsabilidade do 
Estado, mas agora transferidas ("subsidiarizadas") para a esfera das preocupações individualizadas" (BAUMAN, 2013, p. 26). Segundo o sociólogo polonês, de forma ambivalente, a segurança existencial foi individualizada, favorecendo a proliferação de sentimento de insegurança e medos coletivos.

Examinando atentamente as políticas de ampliação da jornada escolar, percebemos que temáticas relacionadas aos medos coletivos adquirem centralidade. Doenças, obesidade, riscos ambientais, danos urbanos ou sustentabilidade foram temas privilegiados em algumas práticas escolares examinadas. A promoção de uma pedagogia das proteções, nas instituições escolares que ampliaram sua jornada, desencadearam a realização de projetos de intervenção comunitária, que colocavam como meta a proteção social dos jovens das periferias urbanas, posicionados em contextos de vulnerabilidade. Não encontramos critérios epistemológicos ou políticos que justificavam a seleção de tais conhecimentos escolares.

\section{Escola e desenvolvimento: o Programa Ensino Médio Inovador (PROEMI)}

Outra política curricular destinada ao Ensino Médio, implementada no Estado do Rio Grande do Sul, é o Programa Ensino Médio Inovador (PROEMI). Trata-se de um dos programas ministeriais que mais tem crescido nos últimos anos. Criado em 2009, já no ano de 2012, quando iniciamos esta investigação, atendia cerca de duas mil escolas em todo o País, o que correspondia a cerca de $10 \%$ das escolas públicas de Ensino Médio. O Estado do Rio Grande do Sul vinculou-se ao programa no final do ano de 2011 e as escolas iniciaram a implementação no ano letivo de 2012. Nessa fase inicial de implementação estão sendo atendidas as escolas que apresentam baixo desempenho no IDEB, vinculando-se diretamente às problemáticas do abandono escolar e do baixo desempenho dos estudantes. Do ponto de vista curricular, o PROEMI propõe-se a ampliar a oferta de disciplinas escolares alternativas, bem como aumentar a jornada escolar através de estratégias que objetivam tornar o currículo escolar mais atraente.

O PROEMI, em seu documento orientador, assinala seu papel de indutor das políticas curriculares para o Ensino Médio na medida em que estabelece que sua atuação "converge para o apoio técnico e financeiro ao desenvolvimento de projetos que visem o aprimoramento de propostas curriculares para o Ensino Médio, capazes de disseminar nos respectivos sistemas a cultura de um currículo dinâmico, flexível e compatível com as exigências da sociedade contemporânea" (BRASIL, 2009, p. 3). Ao oferecer apoio técnico e financeiro, o programa estimula os sistemas de ensino a promoverem propostas organizativas qualificadas que 
se proponham a combater as desigualdades educacionais materializadas nesta etapa da Educação Básica, assim como que reconheçam o Ensino Médio como um aspecto estratégico para o desenvolvimento do País.

O desafio posto está em "fomentar as bases para uma nova escola de Ensino Médio" (BRASIL, 2009, p. 7). Nessa direção, o PROEMI sugere o desenvolvimento de organizações curriculares interdisciplinares, que mobilizem de forma integrada diferentes saberes, competências, valores e práticas e que tenham em seu horizonte a construção de uma escola com qualidade social. Estimulam-se, através do programa, novas formas de organização dos currículos escolares, articuladas com atividades integradoras, que fortaleçam as inter-relações entre as dimensões constituintes do Ensino Médio, a saber: trabalho, ciência, tecnologia e cultura.

Considerando a direção acima descrita, o programa estabelece algumas condições básicas que devem orientar os sistemas de ensino e os diferentes projetos escolares para sua implantação. Elencamos abaixo algumas dessas condições.

a) Carga horária de 3.000 (três mil horas), entendendo-se por 2.400 horas obrigatórias, acrescidas de 600 horas a serem implantadas de forma gradativa;

b) Foco na leitura como elemento de interpretação e de ampliação da visão de mundo, basilar para todas as disciplinas;

c) Atividades teórico-práticas apoiadas em laboratórios de ciências, matemática e outros que estimulem processos de aprendizagem nas diferentes áreas do conhecimento;

d) Fomento às atividades de produção artística que promovam a ampliação do universo cultural do aluno;

e) Oferta de atividades optativas, que poderão estar estruturadas em disciplinas, se assim vierem a se constituir, eletivas pelos estudantes, sistematizadas e articuladas com os componentes curriculares obrigatórios (BRASIL, 2009, p. 10-11).

Notamos imediatamente que o primeiro compromisso das escolas e sistemas de ensino participantes do PROEMI é a ampliação da jornada escolar. No Estado do Rio Grande do Sul, a implementação dessa política tem convergido com a própria 
reforma da rede pública estadual, nomeada como Ensino Médio Politécnico, que exploraremos a seguir. Ao examinarmos as concepções de conhecimento escolar, constatamos que, na implementação deste programa, havia uma tendência de atividades que buscassem a inovação curricular, através de um enfoque na resolução de problemas e de práticas curriculares dinâmicas e flexíveis. A opção por estas práticas é justificada pela necessidade de adequar os currículos do Ensino Médio às demandas da sociedade e da economia contemporâneas, com vistas ao seu desenvolvimento.

Nas práticas curriculares, para além da ênfase metodológica na resolução de problemas, deparamo-nos com atividades sobre educação financeira, educação empreendedora, desenvolvimento local e inovações tecnocientíficas. Do ponto de vista teórico, ao observar a produção subjetiva que perfaz o mundo do trabalho no capitalismo flexível, o sociólogo Sennett (1999) enfatiza como característica central desse cenário a disposição ao risco. O sujeito fabricado nesse jogo de relações busca permanentemente as inovações, não se apega a estruturas burocráticas ou a experiências duráveis. Vive a imediaticidade visando novas oportunidades e mudanças que podem ocorrer em qualquer tempo. As relações entre educação e desenvolvimento, evidenciada na busca de um currículo flexível para o Ensino Médio, pode conduzir a formas curriculares centradas na resolução de problemas e na formação de sujeitos que investem em si mesmos na busca por inovações permanentes.

\section{Ensino Médio Politécnico: conhecimento e customização curricular}

Além das políticas curriculares acima indicadas, ainda encontramos contemporaneamente a implementação de uma reforma curricular no Ensino Médio em nosso contexto investigativo. Durante o ano de 2011, o Estado do Rio Grande do Sul lançou uma política de reforma dos currículos escolares do Ensino Médio. Tomando como ponto de partida a possibilidade de estabelecer uma proposta alternativa para a referida etapa da Educação Básica, o Ensino Médio Politécnico atribui centralidade à perspectiva da resolução de problemas da realidade através do diálogo entre os nomeados conhecimento formal e o conhecimento produzido na vida social. Sob inspiração teórica do progressivismo pedagógico, em suas diferentes nuances, a proposta curricular propõe que as instituições escolares realizem uma pesquisa socioantropológica para "desvelar a realidade e o trabalho dos professores, pela interdisciplinaridade, produzindo os reflexos da ação articulada dos diferentes conhecimentos por suas disciplinas e respectivas áreas" (RIO GRANDE DO SUL, 2012a, p. 2). O Ensino Médio Politécnico sugere, então, que a construção do conhecimento pelo estudante é capaz 
de transformar a realidade social e resolver problemas. A interdisciplinaridade e o educar pela pesquisa são as estratégias mobilizadas para articular as dimensões curriculares da ciência, da tecnologia, da cultura e do trabalho.

Um dos dispositivos ligados a essa proposição é a ampliação dos tempos escolares. A partir da reforma a organização curricular nas escolas públicas estaduais do Rio Grande do Sul passa a ser de, no mínimo, trinta horas-aula semanais. Segundo a documentação que a orienta, essa ampliação é derivada de uma perspectiva pedagógica cidadã que visa "assegurar o acesso à escola, ao conhecimento, à aprendizagem e à permanência do aluno na escola até finalizar seus estudos" (RIO GRANDE DO SUL, 2012a, p. 2). Aumentar a jornada escolar implicaria em propiciar aos estudantes "inserção social e cidadania", fazendo com que a escola dialogue mais sistematicamente com o mundo do trabalho e com os avanços tecnocientíficos.

Acompanha a ampliação da jornada a criação de Seminários Integrados elaborados a partir dos projetos de pesquisa realizados pelos estudantes. Tais seminários propõem-se a qualificar as relações entre teoria e prática no Ensino Médio, na medida em que partem dos interesses e das inquietações dos sujeitos escolares e que têm "como estratégia de trazer o mundo real e dar vida aos conhecimentos formais" (RIO GRANDE DO SUL, 2012b, p. 2). Os seminários correspondem, ao longo dos três anos letivos, a aproximadamente $50 \%$ da carga horária de aulas oferecidas aos estudantes. Podem ser traduzidos, além dos projetos de pesquisa, em práticas, vivências, estágios e visitas que poderão ocorrer fora da escola e fora do turno de aula frequentado pelos estudantes. Trazem como intencionalidade pedagógica, dentre outros aspectos, o desenvolvimento da cooperação, do protagonismo juvenil e do entendimento da escola como uma comunidade de aprendentes.

A política curricular do Ensino Médio do Rio Grande do Sul está em processo de implementação e as escolas estão, gradualmente, vinculando-se ao novo arranjo organizativo. A implantação definitiva acontecerá em 2014, quando todos os estudantes estarão integrados às novas condições. Inquieta-nos, nesse momento, os modos de seleção e de organização do conhecimento escolar aqui desencadeados, visto que, para além da ampliação da jornada, uma parte significativa da carga horária é dedicada aos Seminários Integrados, uma prática curricular derivada da escolha dos estudantes a partir de suas experiências coletivas. Reiteramos ainda que há inúmeras aproximações dessa proposta aos Protótipos Curriculares produzidos pela Unesco e descritos na seção anterior. Para refletir sobre o conhecimento escolar aqui mobilizado, desperta nossa atenção o amplo processo 
de personalização dos percursos. Silva (2014), ao examinar a referida política, sugere que são colocados em ação "dispositivos de customização curricular", nos quais "tal política favorece uma intensa flexibilização dos processos formativos, permitindo que os estudantes possam escolher livremente os aspectos concernentes à sua formação escolar” (p. 147).

\section{Em busca da justiça curricular: provocações finais}

Ao revisarmos as concepções de conhecimento escolar mobilizadas nas políticas curriculares de ampliação da jornada para o Ensino Médio, em desenvolvimento no Estado do Rio Grande do Sul, constatamos que diferentes critérios são utilizados para a seleção dos conhecimentos escolares. Sob diferentes formatos, percebemos que a proteção social, o desenvolvimento econômico e a personalização dos percursos são algumas das racionalidades orientadoras das referidas políticas. Em comum às diferentes políticas, podemos indicar a ausência de uma concepção do conhecimento escolar dimensionada em sua objetividade, ao mesmo tempo em que seja justificada pelo seu caráter formativo. Os processos de seleção dos conhecimentos são regidos por sistemas de raciocínio pedagógico produzidos de forma exógena aos processos escolares, direcionando-os para o atendimento de demandas sociais e econômicas. Em nossa leitura, indicamos a ausência de critérios epistemológicos e políticos que sustentem as pautas formativas definidas nas políticas curriculares examinadas. Afinal, se a jornada escolar está sendo ampliada, precisamos dimensionar suas condições formativas.

Nessa direção, para concluirmos o presente texto, sentimos a necessidade de revitalizar o conceito de 'justiça curricular', tomando-o enquanto uma ferramenta crítica para pensarmos de outros modos os currículos escolares na Contemporaneidade. Seguindo as conhecidas problematizações de Connell (1997), podemos considerar que, mesmo sendo fundamentais, as políticas educativas alicerçadas nas concepções da justiça distributiva demandam um conceito complementar - a justiça curricular. As políticas produzidas desde os anos de 1970, no contexto estadunidense, mobilizavam estratégias de educação compensatória que intencionavam, ao dirigirem-se aos grupos desfavorecidos, constituir-se em uma ruptura com o ciclo da pobreza e eliminar as suas heranças (CONNELL, 1997). De acordo com o autor, as hipóteses da educação compensatória estavam ancoradas em posicionamentos equivocados, a saber: o entendimento de que as desigualdades escolares eram uma questão referente às minorias, a perspectiva de que "os pobres são culturalmente diferentes da maioria" (p. 35), ou ainda de que as reformas educativas eram um problema de natureza técnica. 
Diferenciando-se dos sociólogos da reprodução, Connell (1997) argumentava que "a educação não é o espelho das desigualdades econômicas ou culturais" (p. 40), uma vez que as instituições escolares também produzem suas próprias desigualdades. Ao legitimar determinadas desigualdades, "os sistemas educativos fomentam constantemente a crença que as pessoas favorecidas na distribuição dos bens sociais merecem essas vantagens" (CONNELL, 1997, p. 41). Assim sendo, as instituições escolares oferecem tratamentos diferenciados aos seus estudantes, fabricando identidades sociais que desacreditam determinados sujeitos em detrimento de outros. Em razão desses aspectos que Connell entende que a mobilização de estratégias compensatórias parece ser insuficiente na construção de uma escola justa. Na acepção do autor, precisamos tratar com maior efetividade as questões curriculares, sobretudo os modos de seleção e de organização do conhecimento a ser ensinado. Para o tratamento dessa questão, Connell (1997) indica a perspectiva de seguirmos planejando "programas de aprendizagem comuns" (p. 53). Mesmo reconhecendo que o currículo incorpora relações de hegemonia, o autor alerta-nos para os "perigos" da construção de currículos relativistas, que pouco reforçam a dimensão social do conhecimento ensinado na escola. Em outras palavras, "as aprendizagens comuns não podem definir-se a partir de definições abstratas das necessidades da pessoa, como se a criança se desenvolvesse em um vazio social" (CONNELL, 1997, p.53). A argumentação de Connell nos conduz a pensar que a construção de um currículo que supere as atuais relações hegemônicas não implica em negligenciar a questão objetiva do conhecimento.

O desafio de superar as concepções relativistas nos Estudos Curriculares, assim como a problematização das desigualdades que perfazem os cotidianos escolares, sob essa leitura, apresenta-se como uma possibilidade de mudança educacional. Assim, ao perspectivarmos a justiça curricular nas práticas de ampliação da jornada escolar, postulamos a relevância de construirmos uma forma de organizar os conteúdos e os métodos que se sustente na experiência das pessoas desfavorecidas, que se estenda a todo o sistema e não fique restrita a determinados territórios. Uma estratégia, por conseguinte, que pretende uma reconstrução prática da educação, que outorgue uma certa vantagem aos grupos atualmente desfavorecidos (CONNELL, 1997, p. 57).

Nessa direção, a centralidade do conhecimento escolar nas políticas de ampliação da jornada escolar para o Ensino Médio, no contexto brasileiro, apresenta-se como uma indispensável ferramenta para a efetivação de uma escola curricularmente justa. 


\section{Policies for extending high school hours in Rio Grande do Sul: a study on school knowledge}

\section{Abstract}

This study aims to map political strategies for the constitution of school knowledge in policies intended to extend high school hours in Rio Grande do Sul, considering curriculum policies over the last decade (2002-2012). To this end, this study has adopted the perspective of Curriculum Studies, particularly the branch associated with the critical tradition, either through sociological studies of school knowledge or political studies of the school institution in neoliberal societies. It has been noted that social protection, economic development, and pathway customization are some of the political rationalities that have guided such policies in different structures. As a shared aspect among these different policies, it has been possible to indicate the lack of objective conception of school knowledge and, at the same time, one that is justified by its educative character. The processes of knowledge selection have been guided by systems of pedagogical reasoning external to school processes, thus directing them to fulfill social and economic demands.

Keywords: Curriculum policies. School knowledge. High school.

\section{Políticas destinadas a ampliar la jornada escolar en la educación secundaria, en Rio Grande do Sul: un estudio sobre el conocimiento escolar}

\section{Resumen}

En este artículo se pretende trazar un mapa de las estrategias politicas de incorporación de conocimiento escolar en las políticas de ampliación de la jornada para la educación secundaria en el estado de Rio Grande do Sul, dada la configuración de las políticas curriculares de la última década (2002-2012). Con esta intención, el estudio se enmarca dentro del campo de los estudios curriculares, en especial en los relacionados con la tradición crítica, ya sea a través de los estudios sociológicos del conocimiento escolar, o a partir de los estudios de políticas de la institución educativa en las sociedades neoliberales. Bajo diferentes formatos, se señaló que la protección social, el desarrollo económico y la personalización de las rutas son algunas de las racionalidades políticas orientadoras de las referidas políticas. En general, en las diferentes políticas, se puede indicar la ausencia de una concepción del conocimiento escolar a la medida de su objetividad y, al mismo tiempo, justificada por su carácter formativo. Los procesos de selección de los conocimientos se rigen por sistemas de razonamiento pedagógico producidos de manera exógena en los procesos escolares, orientándolas para satisfacer las demandas sociales y económicas.

Palabras clave: Políticas curriculares. Conocimiento escolar. Educación secundaria. 


\section{Referências}

BALL, S. Performatividades e fabricações na Economia Educacional: rumo a uma sociedade performativa. Educação e Realidade, Porto Alegre, v. 35, n. 2, p. 37-55, maio 2010 .

. Privatising education, privatising education policy, privatising educational research: network governance and the "competition state". Journal of Educational Policy, London, v. 24, n. 1, p. 83-99, 2009.

BALL, S.; MAINARDES, J. (Orgs.). Politicas educacionais: questões e dilemas. São Paulo: Cortez, 2011.

BAUMAN, Z. Modernidade líquida. Rio de Janeiro: Zahar, 2003.

. Vigilância líquida: diálogos com David Lyon. Rio de Janeiro:

Zahar, 2013.

BOMENY, H. Salvar pela escola: programa especial de educação. Sociologia, Problemas e Práticas, Coimbra, n. 55, p. 41-67, 2007.

BRANDÃO, Z. Escola de tempo integral e cidadania escolar. Em Aberto, Brasília, v. 22, n. 80, p. 97-108, abr. 2009.

BRASIL. Lei no 9.394, de 20 de dezembro de1996. Estabelece as diretrizes e bases da educação nacional. Diário Oficial da União, Brasília, DF. 23 dez. 1996.

. Ministério da Educação e Cultura. Programa Ensino Médio

Inovador: documento orientador. Brasília, DF, 2009.

. Ministério da Educação e Cultura. Conselho Nacional de Educação. Diretrizes Curriculares Nacionais para o Ensino Médio. Brasília: CNE, 2012.

CAMBI, F. História da pedagogia. São Paulo: Ed. UNESP, 1999.

CASTRO, M. et al. Escola Estadual Neusa Mari Pacheco: a scholl where participation makes a difference. JISTE. Journal of the International Society for Teacher Education, v. 15, p. 76-81, 2011.

CATABRINNI, U. L'Ecole du tempo pieno em Italie. In: COMPÈRE, M. Historie du temps scolaire em Europe. Paris: Économica, 1997. p. 313-42.

CAVALIERE, A. Escolas de tempo integral versus alunos em tempo integral. Em Aberto, Brasília, v. 22, n. 80, p. 51-83, abr. 2009. 
. Tempo de escola e qualidade na educação pública. Educação \& Sociedade, Campinas, v. 28, n. 100, p. 1015-35, out. 2007.

CHARLOT, B. A escola e o trabalho dos alunos. Sísifo - Revista de Ciências da Educação, Lisboa, n. 10, p. 89-96, set. 2009.

COELHO, L. História(s) da educação integral. Em Aberto, Brasília, v. 22, n. 80, p. 83-96, abr. 2009.

CONNEL, R. W. Escuelas y justicia social. Madrid: Morata, 1997.

DALE, R. Globalização e educação: demonstrando a existência de uma "cultura educacional mundial comum" ou localizando uma "uma agenda globalmente estruturada para a educação"?. Educação \& Sociedade, Campinas, v. 25, n. 87, p. 423-460, maio 2004.

DIAZ-BARRIGA, A. Currículo, escuelas de pensamiento y su expresión en la tensión entre saberes conceptuales y práticos. Currículo sem Fronteiras, v. 13, n. 3, p. 346-60, set. 2013.

DUSSEL, I. A transmissão cultural assediada: metamorfoses da cultura comum na escola. Cadernos de Pesquisa, São Paulo, v. 39, n. 137, p. 351-65, maio 2009.

FABRIS, E. A escola contemporânea: um espaço de convivência?. In: REUNIÃO ANUAL DA ANPED, 30., 2007, Caxambu, MG. Anais... Rio de Janeiro: ANPED, 2007. p. 1-17.

FABRIS, E.; TRAVERSINI, C. Conhecimentos escolares sob outras configurações: efeitos das movimentações disciplinares e de controle. In: REUNIÃO ANUAL DA ANPED, 34., 2011, Natal. Anais... Rio de Janeiro: ANPED, 2011. p. 1-15.

FINOCCHIO, S. Una cartografia de saberes escolares en movimiento para América Latina. Propuesta Educativa, Buenos Aires, v. 34, n. 2, p. 65-76, 2010.

GABRIEL, C.; CASTRO, M. Conhecimento escolar: objeto incontornável da agenda política educacional contemporânea. Educação em Questão, Natal, v. 45 , n. 31, p. 82-110, 2013.

LIBÂNEO, J. O dualismo perverso da escola pública brasileira: escola do conhecimento para os ricos, escola do acolhimento social para os pobres. Educação e Pesquisa, São Paulo, v. 38, n. 1, p. 13-28, abr. 2012. 
LIMA, L. Aprender para ganhar, conhecer para competir. São Paulo: Cortez, 2012.

LOPES, A.; MACEDO, E. Teorias do currículo. São Paulo: Cortez, 2011.

MAURÍCIO, L. Literatura e representações da escola pública de horário integral. Revista Brasileira de Educação, Rio de Janeiro, n. 27, p. 40-56, set. 2004. doi:10.1590/S1413-24782004000300004

MIRANDA, M. Sobre tempos e espaços da escola: do princípio do conhecimento ao princípio da socialidade. Educação \& Sociedade, Campinas, v. 26, n. 91, p. 638-51, maio 2005. doi:10.1590/S0101-73302005000200017

MOLL, J. Caminhos da educação integral no Brasil. Porto Alegre: Penso, 2012.

MOREIRA, A. F. B. A importância do conhecimento escolar em propostas curriculares alternativas. Educação em Revista, Belo Horizonte, v. 45, p. 265-90, jun. 2007. doi:10.1590/S0102-46982007000100014

. Currículo e gestão: propondo uma parceria. Ensaio: Avaliação e Políticas Públicas em Educação, Rio de Janeiro, v. 21, n. 80, p. 547-562, jul. 2013. doi:10.1590/S0104-40362013000300009

. Lendo Stella: um mote para pensar o fundamental na escola de ensino fundamental. Revista da FAEEBA - Educação e Contemporaneidade, Salvador, v. 19, n. 34, p. 193-205, 2010.

. Qualidade na educação e no currículo: tensões e desafios. Revista Educação On-line (PUCRJ), Rio de Janeiro, v. 4, p. 1-14, 2009.

MÜLLER, J. Reclaiming knowledge: social theory, curriculum and education policy. Londres: Routledge, 2000.

MÜLLER, J. Revisitando o progressivismo: Ethos, política, Pathos. In: GARCIA, R. L.; MOREIRA, A. F. B. (Orgs.). Currículo na contemporaneidade: incertezas e desafios. São Paulo: Cortez, 2003. p. 293-318.

NARODOWSKI, M.; BRAILOVSKI, D. La cuestión del fin de la razón de estado en la historia de la escolarización. In: NARODOWSKI, M.; BRAILOVSKI, D. (Orgs.). Dolor de escuela. Buenos Aires: Prometeo, 2006. p. 61-80.

NÓVOA, A. Professores: imagens do futuro presente. Lisboa: Educa, 2009. 
OLIVEIRA, D. A nova regulação de forças no interior da escola: carreira, formação e avaliação docente. Revista Brasileira de Política e Administração Educacional, Porto Alegre, v. 27, n. 1, p. 25-38, jan./abr. 2011.

PACHECO, J. Políticas curriculares: referenciais para análise. Porto Alegre: Artmed, 2003.

POPKEWITZ, T. El cosmopolitismo y la era de la reforma escolar. Madrid: Morata, 2009.

. La historia del curriculum: la educación en los Estados Unidos a principios del siglo XX. Profesorado: revista del curriculum y formación del profesorado, Granada, v. 11, n. 3, p. 1-13, 2010.

- Reforma, conhecimento pedagógico e administração social da individualidade: a educação escolar como efeito de poder. In: IMBERNÓN, F. (Org.). A educação no século XXI: os desafios do futuro imediato. Porto Alegre: Artmed, 2000. p. 141-70.

RIO GRANDE DO SUL. Secretaria Estadual da Educação. Ensino médio politécnico: síntese da proposta. Porto Alegre, 2012b.

. Secretaria Estadual da Educação. Proposta pedagógica para o ensino médio politécnico. Porto Alegre, 2012a.

ROBERTSON, S. A estranha não morte da privatização neoliberal na Estratégia 2020 para a educação do Banco Mundial. Revista Brasileira de Educação, Rio de Janeiro, v. 17, n. 50, p. 283-302, maio 2012.

SACRISTÁN, G. El valor del tiempo en educación. Madrid: Morata, 2008.

SENNETT, R. A corrosão do caráter: consequências pessoais do trabalho no novo capitalismo. Rio de Janeiro: Record, 1999.

. A cultura do novo capitalismo. Rio de Janeiro: Record, 2006.

SHIROMA, E.; GARCIA, R.; CAMPOS, R. Conversão das 'almas' pela liturgia da palavra: uma análise do discurso do movimento Todos pela Educação. In: BALL, S.; MAINARDES, J. (Orgs.). Políticas educacionais: questões e dilemas. São Paulo: Cortez, 2011. p. 222-48. 
SILVA, R. R. D. Políticas de constituição do conhecimento escolar para o Ensino Médio no Rio Grande do Sul: uma analítica de currículo. Educação em Revista, Belo Horizonte, v. 30, n.1, p. 127-58, jan./mar. 2014. doi:10.1590/S0102-46982014000100006

SILVA, R. R. D.; PEREIRA, A. Políticas de constituição do conhecimento escolar na pesquisa educacional brasileira. Cadernos de Pesquisa, São Paulo, v. 43, n. 150 , p. $884-905$, set./dez. 2013. doi:10.1590/S0100-15742013000300008

SIMONS, M.; MASSCHELEIN, J. The leaning society and governmentality: an introduction. Educational Philosophy and Theory, Auckland, v. 39, n. 4, p. 417-30, 2006.

SLOTERDJIK, P. Sobre la mejora de la buena nueva: el "quinto" evangelio según Nietzsche. Madrid: Siruela, 2005.

TEIXEIRA, A. Educação não é privilégio. 5a. ed. Rio de Janeiro: Editora da UFRJ, 1994.

Nacional, 1978.

. Pequena introdução à filosofia da educação. São Paulo:

UNESCO - ORGANIZAÇÃO DAS NAÇÕES UNIDAS PARA A EDUCAÇÃO, A CIÊNCIA E A CULTURA. Protótipos curriculares de Ensino Médio e Ensino Médio Integrado: resumo executivo. Brasília, DF, 2011.

Reforma da educação secundária: rumo à convergência entre a aquisição de conhecimento e o desenvolvimento de habilidade. Brasília, DF, 2008.

YATES, L.; COLLINS, C. A ausência de conhecimento nas reformas curriculares australianas. Revista E-curriculum, São Paulo, v. 9, n. 2, p. 1-23, maio 2012.

YOUNG, M. Conhecimento e currículo: do socioconstrutivismo ao realismo social na sociologia da educação. Porto: Porto, 2010.

. O futuro da educação em uma sociedade do conhecimento: a defesa radical de um currículo disciplinar. Cadernos de Educação, Pelotas, v. 38, p. 395-416, jan./abr. 2011.

. Para que servem as escolas?. Educação \&

Sociedade, Campinas, v. 28, n. 101, p. 1287-302, set./dez. 2007. doi:10.1590/S0101-73302007000400002 


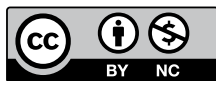

\section{Informações do autor}

Roberto Rafael Dias da Silva: Doutor em Educação, Universidade do Vale do Rio dos Sinos - UNISINOS. Professor do Programa de Pós-Graduação em Educação, Universidade de Caxias do Sul - UCS. Contato: rrdsilva@ucs.br; robertoddsilva@yahoo.com.br 